\title{
Word naming and psycholinguistic norms: Chinese
}

\author{
YouYi LiU ANd Hua SHu \\ Beijing Normal University, Beijing, China \\ AND \\ Ping LI \\ University of Richmond, Richmond, Virginia
}

\begin{abstract}
In this article, we present normative data for 2,423 Chinese single-character words. For each word, we report values for the following 15 variables: word frequency, cumulative frequency, homophone density, phonological frequency, age of learning, age of acquisition, number of word formations, number of meanings, number of components, number of strokes, familiarity, concreteness, imageability, regularity, and initial phoneme. To validate the norms, we collected word-naming latencies. Factor analysis and multiple regression analysis show that naming latencies of Chinese single-character words are predicted by frequency, semantics, visual features, and consistency, but not by phonology. These analyses show distinct patterns in word naming between Chinese and alphabetic languages and demonstrate the utility of normative data in the study of nonalphabetic orthographic processing.
\end{abstract}

Recent research has shown that many variables affect speakers' performance in word-naming tasks. As Balota, Cortese, Sergent-Marshall, Spieler, and Yap (2004) pointed out, such variables could include factors at various levels - for example, the surface level (initial phoneme), the lexical level (e.g., word length, word frequency, and spelling-to-sound consistency), and the semantic level (e.g., imageability and concreteness). These levels are not mutually exclusive and in fact sometimes overlap with one another-for example, word frequency could influence word naming at both the lexical and the semantic level.

Previous studies in alphabetic languages, especially those languages with transparent orthographic systems, have suggested that lexical-level variables play more important roles than semantic-level variables in word-naming tasks (e.g., Balota et al., 2004; Barca, Burani, \& Arduino, 2002; Frost, 1998; Lukatela \& Turvey, 1994; Van Orden, Pennington, \& Stone, 1990). For example, in Italian, a language with transparent orthography-phonology correspondences, Barca et al. (2002) found that only lexical-level variables (e.g., frequency, word length, and neighborhood size) had significant effects on the naming of nouns, whereas semantic variables (e.g., imageability and concreteness) had negligible influences. In English, in which the orthography-phonology relationship is less transparent, Balota et al. (2004) found that surface-, lexical-, and semantic-level variables all have an impact on word-naming performances. Semantic effects, however, have been shown by a few studies to be significant only for low-frequency and exception words (e.g., Strain, Patterson, \& Seidenberg, 1995, 2002).
Previous studies have also examined variables on word/ character ${ }^{1}$ naming in nonalphabetic languages such as Chinese and Japanese. These studies have shown that surface and lexical variables such as word/character frequency, phonetic regularity, number of strokes, and number of components are also important for Chinese word naming (Leck, Weekes, \& Chen, 1995; Zhou, Shu, Bi, \& Shi, 1999). Other variables, such as initial phoneme of a syllable, age of acquisition, homophone density, and phonological frequency, have only recently been examined and shown to be important (Chen, Wang, Wang, \& Peng, 2004; Liu, Zhang, \& Shu, 2006; Ziegler, Tan, Perry, \& Montant, 2000). Finally, semantic-level variables such as imageability and concreteness have also recently been found to be important in the processing of Japanese Kanji (Chinese characters; Shibahara, Zorzi, Hill, Wydell, \& Butterworth, 2003), as well as in word naming and lexical decision in Chinese (Chen \& Peng, 1998; see also Q. Zhang \& Zhang, 1997). A major finding from Shibahara et al. (2003) was that semantic effects (i.e., imageability effect) were stronger in Kanji processing than in word processing in English.

However, few previous studies have attempted to relate their experimental patterns (usually based on a small set of characters/words) to large-scale normative data, since collection of such normative data is time consuming and labor intensive. The present study fills this gap. In particular, we examined a large set of potential variables that could contribute to word-naming performances by Chinese speakers. In our study, we first collected normative data for the most common single-character words in Chinese,

Y. Liu, psykylin@gmail.com 
and then explored for these words the relationship between variables in the normative data and word-naming latencies from experimental data. The large-scale normative data derived from our study have obvious practical significance for psycholinguistic research using Chinese characters/words. Moreover, our analyses of the relationships between normative data and word-naming latencies could also yield results that shed light on theoretical issues regarding universality versus linguistic specificity in lexical processing.

\section{METHOD}

\section{Materials}

Given that monosyllabic words have been the focus of previous studies in both alphabetic and nonalphabetic languages, our study examined only single-character words, which are comparable to monosyllabic words in alphabetic languages. A total of 2,423 single-character words were selected from the Language Corpus System of Modern Chinese Studies (hereafter, LCSMCS; Sun, Huang, Sun, Li, \& Xing, 1997). The corpus includes about 46,000 word types, of which about 5,300 are single-character words. Three major lexical categories-nouns, verbs, and adjectives - are the focus of our investigation. Of the 2,423 single-character words selected for this study, there were 977 nouns, 1,133 verbs, and 313 adjectives. Since lexical ambiguity is a pervasive phenomenon in Chinese (see P. Li, Jin, \& Tan, 2004; Y. Zhang, Wu, \& Yip, 2006), we identified a significant number of ambiguous words that could be used in more than one grammatical category (e.g., nouns and verbs). Of the 2,423 words selected, 604 were words that can occur in two different grammatical categories, and 351 were words that can occur in three or more categories. For these grammatically ambiguous words, we identified the dominant grammatical category (or categories) according to usage frequency in LCSMCS (Sun et al., 1997), and then rated the corresponding age of acquisition, familiarity, concreteness, and imageability for each dominant category.

\section{Variables}

On the basis of previous studies, and upon considering the characteristics of Chinese characters, we chose the following 15 variables for our normative study (grouped below according to the similarities of the variables):

1. Initial phoneme. A typical Chinese monosyllable consists of three parts: initial (onset), final (rhyme), and tone. The initial phoneme is usually a consonant, but in some cases there is no onset consonant and the initial phoneme is a vowel. The final consists of at least the nucleus vowel, sometimes with or without a medial or nasal ending. Lexical tones are suprasegmental, imposed on the initial and the final. According to the phonetic analysis of Chinese consonants based on place of articulation (Luo \& Wang, 2002), we classified the onset phonemes of Chinese words into seven types: bilabial, labiodentals, dental-veolar, alveolar, retroflex, dorsal, and velar. When no onset consonant was present in the syllable, the vowel was counted as the eighth type.

2. Regularity. About $80 \%$ of Chinese characters are phonetic compound characters that consist of a phonetic part and a semantic part (Y. Li \& Kang, 1993). These characters are sometimes also called phonograms or ideophonetic (see Peng \& Jiang, 2006). They can be divided into three categories, based on whether the pronunciation of the phonetic part is the same as the pronunciation of the whole character in which the phonetic part appears: regular (such as 清 "qingl," which is pronounced the same as its phonetic part 青 “qingl”), irregular (such as 猜 “cail," which is pronounced differently from its phonetic part 青 “qingl”), and bound (such as 峰 “fengl," in which the phonetic part [夆] has neither a pronunciation nor a meaning of its own in modern Chinese). The other $20 \%$ of characters are nonphonetic compound characters, most of which are simple characters that do not have a separate phonetic part (e.g., 虫 “chong2"). Each character in our normative data was categorized into one of three types, according to the utility of the phonetic part to the whole character: regular, irregular, or other (bound or no phonetic part).
3. Word frequency, cumulative frequency, and number of word formations. The characters in our study can be used as singlecharacter words or as morphemes in multicharacter words, so there are two types of frequency: the frequency of the single-character words (word frequency), and the sum frequency of all of the words in which a character appears (cumulative frequency). The latter type of frequency also depends on the number of words that a character can form (number of word formations). In our normative study, word frequency was based on the data from the LCSMCS (Sun et al., 1997), and cumulative frequency was based on the Balanced Corpus of Modern Chinese (Sun, 2006), the largest electronic database on Chinese to date (with about 660 million characters).

4. Homophone density and phonological frequency. In Chinese, there are many single-character words that are homophones. The size of the largest homophone family ("yi4") reaches 205. The number of homophones is defined as homophone density (see P. Li \& Yip, 1998). Phonological frequency refers to the total frequency of all of the characters that have the same pronunciation. Both homophone density and phonological frequency of the characters were calculated from the Modern Chinese Frequency Dictionary (Wang, 1986).

5. Number of meanings. Some Chinese characters have several meanings. According to the Dictionary of Chinese Character Information (Science Publishers, 1988), about 53\% of Chinese characters have one meaning, $21 \%$ have two meanings, $19 \%$ have three or more meanings, and the remaining $7 \%$ have no meanings of their own (i.e., they are characters bound to other characters to make words). This dictionary subdivided characters into six categories, based on the number of meanings that a character can have: 0 (no meaning), 1 (one meaning), 2 (two meanings), 3 (three to four meanings), 4 (five to eight meanings), and 5 (nine or more meanings).

6. Number of strokes and number of components. The basic ingredients of Chinese characters are strokes. The number of strokes can be as few as 1 and as many as 36 . Strokes make up components (parts or radicals), which can appear recurrently in different characters. These two variables can be used as indices of the visual complexity of characters. For more details on these variables, see Xing, Shu, and $\mathrm{Li}$ (2004) for a summary accessible to English readers.

7. Age of learning. Age of learning refers to the time at which the learner is exposed to a given character, and this is determined by the time when a character is first introduced in standard school textbooks (People's Education Press, 2006). For more details about how textbook-based age of learning can predict character acquisition, see Shu, Chen, Anderson, Wu, and Xuan (2003).

8. Age of acquisition, familiarity, concreteness, and imageability. Age of acquisition refers to the time when the learner has acquired the meaning and pronunciation of the character. ${ }^{2}$ Familiarity, concreteness, and imageability are standard lexical characteristics that have been examined in previous studies of alphabetic languages. The values for these three variables and age of acquisition were obtained by subjective ratings based on the method and procedure of Barca et al. (2002). See more details about the rating study below.

Table 1 presents the descriptive statistics for the numerical variables. The table does not include initial phoneme and regularity, because these are nonnumerical variables.

\section{Participants}

A total of 480 native Chinese speakers (122 males) with a mean age of 20.3 years (range $=18-23$ years) participated in the rating study. A separate group of 39 speakers (19 males) with a mean age of 19.5 years (range $=17-25$ years) participated in the word-naming study. All of the participants were undergraduate or graduate students from Beijing Normal University. They had normal or corrected-tonormal vision, and reported no cognitive or motor problems. They were paid for their participation.

\section{Procedure}

The rating instructions and procedures were similar to those used by Barca et al. (2002). In our rating study, the 2,423 words were split randomly into three groups, for presentation in three different ver- 
sions. Each version had about 800 words and was printed on nine pieces of A4-sized paper. The presentation order of the words was randomized for each version. Each participant rated the words on one of the four variables (i.e., age of acquisition, familiarity, concreteness, and imageability) for all of the words in a version. There were 12 groups of participants (40 per group) in the rating task, such that each item was rated by 40 participants on each of the four variables.

In the word-naming task, the participants were tested one at a time in an experimental room. They were seated about $60 \mathrm{~cm}$ away from the computer screen. A fixation cross was presented on the computer for $500 \mathrm{msec}$, followed by a 120-msec blank, and then followed by the target character, in white against black background. The participants were given a 2 -sec interval to respond before the next trial began. The fixation and stimuli were displayed in 28-point Song font. Stimuli presentation and data recording were controlled by the DMDX system (Forster \& Forster, 2003). The participants were instructed to name the characters as quickly and as accurately as possible into an external microphone that was connected to the DMDX timing box. Each participant received the 2,423 words in randomized order. Practice stimuli were given before the experimental trial began. The experimental session included seven short breaks, to prevent participant fatigue. The entire experimental session lasted about $90 \mathrm{~min}$.

\section{Analyses}

The participants' responses were checked for accuracy by two experimenters offline. For the analyses of the word-naming data, incorrect responses and time-out data were removed (mean error rate for the 2,423 words was $7.9 \%$ ). Data from 4 participants were also removed because of high error rates ( $20 \%$ or more) or long naming latencies (700 msec or longer). Only 2,390 of the 2,423 words entered our final statistical analyses, because 33 words had high error rates (above 50\%). Detailed error rates are not reported here.

Since word frequency distributions tend to follow Zipf's law (Zipf, 1932), and are generally skewed (as was true with our three frequency measures), we calculated the logarithms (base 10) of the word frequency, cumulative frequency, and phonological frequency data. We also log-transformed the distributions of the number of word formations, age of learning, and homophone density data to correct for their positive skewness before running the regression analysis (Hair, Black, Babin, Anderson, \& Tatham, 2006).

\section{RESULTS AND DISCUSSION}

\section{Correlations Among Variables and Naming Latency}

Table 2 presents the correlations (Pearson's $r$ ) among the numerical variables and the harmonic means of the naming latencies for the 2,390 Chinese single-character words.

Table 1

Descriptive Statistics for the 13 Numerical Variables

\begin{tabular}{llrr}
\hline \multicolumn{1}{c}{ Variable } & Acronym & \multicolumn{1}{c}{$M$} & \multicolumn{1}{c}{$S D$} \\
\hline Word frequency* $^{*}$ & $\mathrm{WF}$ & 83.43 & 453.99 \\
Cumulative frequency* $^{*}$ & $\mathrm{CF}$ & 238.34 & 632.05 \\
Phonological frequency* $^{*}$ & $\mathrm{PF}$ & $1,278.99$ & $2,438.36$ \\
Homophone density & $\mathrm{HD}$ & 31.22 & 28.98 \\
Age of learning & $\mathrm{AoL}$ & 6.29 & 5.26 \\
Age of acquisition & $\mathrm{AoA}$ & 4.41 & 0.90 \\
Number of word formations & $\mathrm{NWF}$ & 20.30 & 27.43 \\
Number of meanings & $\mathrm{NM}$ & 2.24 & 1.08 \\
Concreteness & $\mathrm{CON}$ & 5.03 & 1.03 \\
Familiarity & $\mathrm{FAM}$ & 5.97 & 0.74 \\
Imageability & $\mathrm{IMG}$ & 5.30 & 0.96 \\
Number of components & $\mathrm{NC}$ & 3.04 & 1.06 \\
Number of strokes & $\mathrm{NS}$ & 9.81 & 3.40 \\
\hline
\end{tabular}

*The values for the three frequency indices were counted in times/million.

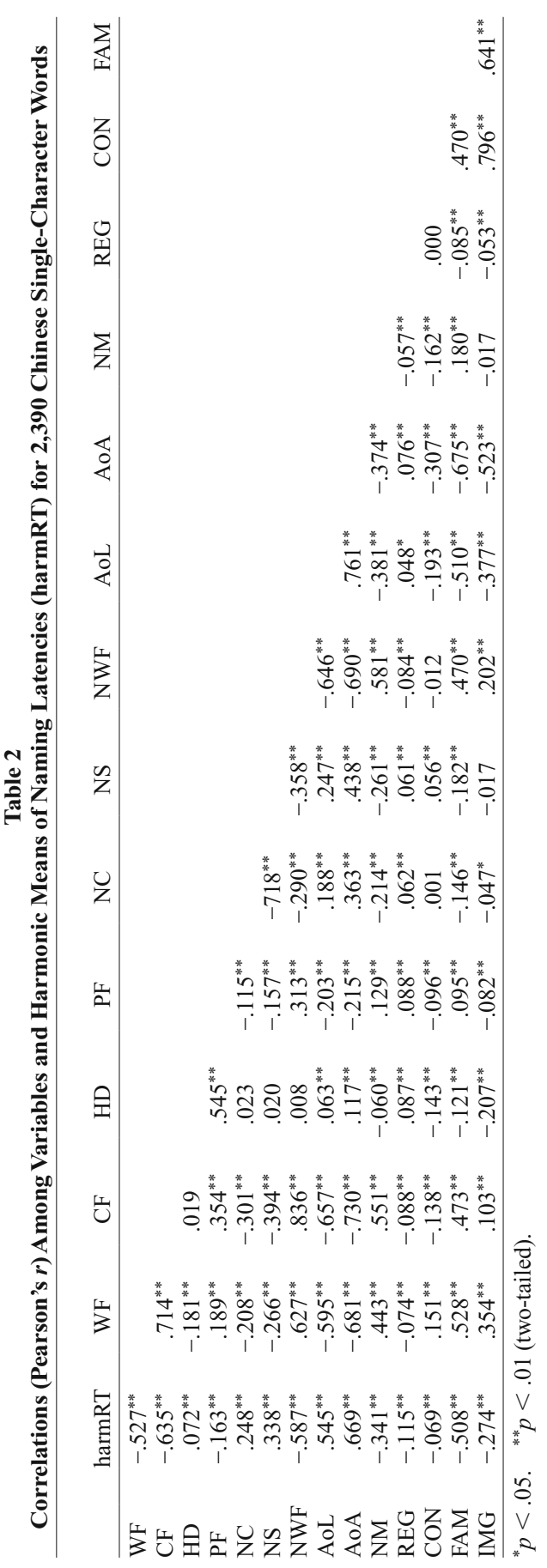

A number of observations can be made about the data in Table 2. First, naming latencies correlated highly with word frequency (WF), cumulative frequency (CF), number of word formations (NWF), age of learning (AoL), age of acquisition (AoA), and familiarity (FAM). These correlations indicate that the words that are named faster tend to be highly frequent, be more familiar, form more words, and be learned and acquired earlier in life. Second, both word frequency and cumulative frequency, which were highly correlated with each other, were highly cor- 
related with several other variables, including number of word formations, age of learning, age of acquisition, number of meanings (NM), and familiarity. These correlations indicate that frequency is inherently related to other lexical characteristics in Chinese. Third, concreteness (CON) and imageability (IMG) were, not surprisingly, highly correlated with one another. Fourth, age of acquisition had high correlations with all of the other variables. Specifically, age of acquisition correlated positively with age of learning and number of strokes (NS), and negatively with cumulative frequency, word frequency, number of word formations, familiarity, and imageability, which suggests that early-acquired words tend to appear early in textbooks, have fewer numbers of strokes, form more multiple-character words, occur more frequently, and be highly familiar and highly imageable.

\section{Multiple Regression Analysis}

To explore the importance of variables that affect word naming in Chinese, we used a multiple regression analysis (MRA). In addition, we wanted to explore the interaction between cumulative frequency and age of acquisition. According to the localized semantic growing network and distributed network plasticity hypotheses, cumulative frequency should interact with age of acquisition (Ellis \& Lambon Ralph, 2000; Hernandez \& Li, 2007; Lambon Ralph \& Ehsan, 2006; P. Li, Farkas, \& MacWhinney, 2004). In our MRA, we followed Aiken and West (1991), who suggested that cumulative frequency and age of acquisition should be centered ${ }^{3}$ before running this type of analysis (see also Young \& Perkins, 2005). This was to avoid collinearity between cumulative frequency, age of acquisition, and the product of cumulative frequency and age of acquisition.

The results of the naming-latency MRA are displayed in Table 3. At Step 1 of our MRA, the initial phoneme (IP) variable was entered into the regression. As expected, the IP variable has a significant role in word naming, which accounted for $5.8 \%$ of the variance in the naming-latency data. At Step 2, we used a stepwise-method MRA to explore the roles of all the other 14 lexical and semantic variables. Ten out of the 14 variables were significant in accounting for the variances in word naming. In terms of the amounts of variances accounted for, the variables can be ordered (in decreasing importance) as follows: age of acquisition (AoA), cumulative frequency $(\mathrm{CF})$, regularity (REG), familiarity (FAM), concreteness (CON), number of strokes (NS), number of word formations (NWF), phonological frequency (PF), imageability (IMG), and number of components (NC). Together, the 10 variables accounted for $55.8 \%$ of the variance, and among these 10 variables, age of acquisition accounted for the largest amount of variance $(44.8 \%)$, and cumulative frequency accounted for an additional $5.6 \%$ of the variance.

At Step 3 of the MRA, we added the interaction of cumulative frequency and age of acquisition to the equation. Table 3 shows that the interaction accounted for an additional amount of variance at a significant level, which suggests that cumulative frequency does interact with age of acquisition, and word naming in Chinese is affected by the
Table 3

\begin{tabular}{|c|c|c|c|}
\hline & $\beta$ & $\mathrm{T}$ & $\Delta R^{2}$ \\
\hline Step 1 & & & .058 \\
\hline Bilabial & -.137 & $-5.733^{* * *}$ & \\
\hline Labiodentals & .040 & 1.899 & \\
\hline Dental-veolar & .076 & $3.361^{* * *}$ & \\
\hline Alveolar & -.133 & $-5.271^{* * *}$ & \\
\hline Dorsal & .069 & $2.716^{* *}$ & \\
\hline Velar & -.048 & $-2.029^{*}$ & \\
\hline Vowels & -.092 & $-3.844^{* * *}$ & \\
\hline Step 2 & & & .558 \\
\hline ÅA & .670 & $46.481^{* * *}$ & .448 \\
\hline $\mathrm{CF}$ & -.348 & $-17.409^{* * *}$ & .056 \\
\hline REG & -.172 & $-12.952^{* * *}$ & .029 \\
\hline FAM & -.132 & $-7.519^{* * *}$ & .010 \\
\hline $\mathrm{CON}$ & .126 & $7.024^{* * *}$ & .008 \\
\hline NS & .048 & $3.229^{* * *}$ & .002 \\
\hline NWF & -.075 & $-3.154^{* *}$ & .002 \\
\hline $\mathrm{PF}$ & .038 & $2.660^{* *}$ & .001 \\
\hline IMG & -.059 & $-2.243^{*}$ & .001 \\
\hline $\mathrm{NC}$ & -.040 & $-2.155^{*}$ & .001 \\
\hline Step 3 & & & .024 \\
\hline CF*AoA & -.163 & $-12.427^{* * *}$ & .024 \\
\hline
\end{tabular}

interaction. Following Aiken and West (1991) and Cohen and Cohen (1983), we could recast the regression equation to probe a significant interaction, and in this case, we used the value of 1 standard deviation $(S D)$ above or below the means to do so, as Aiken and West (1991) suggested. The regression equation could be written as:

$$
\mathrm{RT}=\Delta+b_{1} * \mathrm{AoA}+b_{2} * \mathrm{CF}+b_{3} * \mathrm{AoA} * \mathrm{CF}
$$

The $\Delta$ in the equation contains the constant and all other variables' influences; $b_{1}, b_{2}$, and $b_{3}$ are the unstandardized coefficients in the final regression equation. When considering early-acquired words, the AoA value was substituted by the value $1 S D$ below the mean (i.e., 0 ). When considering late-acquired words, the AoA value was substituted by the value $1 S D$ above the mean. Thus, we have the following two modified formulas in Equation 2, one for earlyacquired words and one for late-acquired words.

$$
\begin{cases}\mathrm{RT}=\Delta-8.35 * \mathrm{CF}-16.43 & \text { Early acquired } \\ \mathrm{RT}=\Delta-28.75 * \mathrm{CF}+16.43 & \text { Late acquired }\end{cases}
$$

We could see that the frequency effect is stronger on late-acquired than on early-acquired words, given that the absolute value of the coefficient is larger for the former (28.75) than the latter (8.35) from the formulas in Equation 2.

\section{Principal Component Factor Analysis}

As discussed earlier, many of the variables of interest in our study are highly correlated with each other (see Table 2), indicating significant collinearity among the variables. To reduce the influence of collinearity and to further identify the general factors that influence word naming, we conducted a principal component factor analysis (Hair et al., 2006). In this analysis, all 15 variables except initial phoneme were simultaneously submitted to factor analysis. The factor scores were then used as pre- 
Table 4

Rotated Factor Loadings for All 14 Predictor Variables

\begin{tabular}{lccccc}
\hline & \multicolumn{5}{c}{ Factor } \\
\cline { 2 - 6 } Variable & Frequency & Semantics & Visual Features & Phonology & Consistency \\
\hline CF & $\mathbf{. 9 0 5}$ & -.021 & -.187 & .156 & -.052 \\
NWF & $\mathbf{. 6 6 7}$ & .059 & -.166 & .134 & -.046 \\
WF & $\mathbf{. 9 5}$ & .247 & -.076 & -.060 & -.014 \\
AoL & -.756 & -.320 & .066 & -.060 & -.010 \\
AoA &.$- \mathbf{7 4 0}$ & -.469 & .292 & -.038 & .018 \\
NM & $\mathbf{. 7 1 3}$ & -.250 & -.100 & -.093 & -.002 \\
IMG & .169 & $\mathbf{. 9 1 4}$ & .011 & -.119 & -.018 \\
CON & -.096 & .910 & .018 & -.070 & .027 \\
FAM & .499 & $\mathbf{. 6 7 6}$ & -.063 & .012 & -.065 \\
NC & -.147 & -.029 & .917 & -.014 & .023 \\
NS & -.251 & .013 & .890 & -.034 & .019 \\
HD & -.120 & -.113 & .026 & .890 & .008 \\
PF & .258 & -.032 & -.078 & .845 & .069 \\
REG & -.054 & -.018 & .035 & .066 &. $\mathbf{9 9 4}$ \\
\% Variance & 30.62 & 18.46 & 12.95 & 11.36 & 7.17 \\
\hline
\end{tabular}

dictors in a confirmatory MRA, with harmonic means of the naming latency as the dependent variable.

Table 4 presents the results of the factor analysis. Five factors were extracted (eigenvalues $>1.0$ ) from the analysis: (1) frequency, with high loadings for cumulative frequency, word frequency, number of word formations, age of acquisition, age of learning, and number of meanings; (2) semantics, with high loadings for imageability, concreteness, and familiarity; (3) visual features, with high loadings for number of components and number of strokes; (4) phonology, with high loadings for homophone density and phonological frequency; and (5) consistency, with high loadings for regularity. These five factors together accounted for $80.56 \%$ of the total variance, of which frequency accounted for $30.62 \%$, semantics $18.46 \%$, visual features $12.95 \%$, phonology $11.36 \%$, and consistency $7.17 \%$. Table 4 also shows that age of acquisition and familiarity both loaded highly on the frequency and semantics factors.

Table 5 presents the results of the factor score-based MRAs. Frequency, semantics, visual features, and consistency all significantly predicted the naming latencies. Together, they accounted for $50 \%$ of the total variance $\left[R^{2}=\right.$ $.50 ; F(5,2383)=476.49, p<.001]$. However, the factor phonology was not significant in the regression. Thus, the regression equation for our Chinese word-naming data could be written as

$$
\begin{aligned}
\mathrm{RT}=532 & -31.05 * \text { frequency } \\
& -10.15 * \text { semantics } \\
& +9.53 * \text { visual features } \\
& -7.37 * \text { consistency. }
\end{aligned}
$$

Table 5

Regression of Factor Scores on Naming Latencies

\begin{tabular}{lrrr}
\hline \multicolumn{1}{c}{ Factor } & \multicolumn{1}{c}{$\mathrm{B}$} & \multicolumn{1}{c}{$\beta$} & \multicolumn{1}{c}{$\mathrm{T}$} \\
\hline Frequency & -31.05 & -0.63 & $-43.51^{* * * *}$ \\
Semantics & -10.15 & -0.21 & $-14.22^{* * *}$ \\
Visual features & 9.53 & 0.19 & $13.35^{* * *}$ \\
Phonology & -1.18 & -0.02 & -1.65 \\
Consistency & -7.37 & -0.15 & $-10.32^{* * *}$ \\
\hline$* * *$
\end{tabular}

${ }^{* * *} p<.001$.

\section{Conclusions}

In this study, we presented normative data of 15 variables for 2,423 Chinese single-character words. Our study is one of the first, and by far the largest, of its kind in the study of Chinese language processing. Although normative data are widely available for alphabetic languages, such data are rare or nonexistent for nonalphabetic languages. Thus, the norms and analyses presented here will be useful to the cognitive and psycholinguistic studies of Chinese and to comparative studies of Chinese and other languages.

To validate the norms, we used 15 variables to predict naming latencies for the 2,423 words, in order to identify the effects of these variables on lexical processing. We conducted both factor analyses and MRAs to show that word-naming latencies are affected by frequency, semantics, visual features, and consistency of Chinese characters. However, the effect of phonology on word naming is not significant. These results distinguish Chinese from alphabetic languages, in which phonological factors and orthographic features play a more significant role than semantic factors (e.g., Barca et al., 2002; Bates, Burani, D'Amico, \& Barca, 2001).

The normative data described in this article are available at cogsci.richmond.edu/. We are currently developing a Web-based interface that will enable users to retrieve online the characteristics of the 15 variables for an even larger set of Chinese words. When it is completed, the interface should function as a Chinese version of the MRC Psycholinguistic Database (www.psy.uwa.edu.au/mrcdatabase/ uwa_mrc.htm) or the English Lexicon Project (elexicon .wustl.edu).

\section{AUTHOR NOTE}

We thank Michael Cortese for comments on the manuscript. This research was supported by Grants 60534080 and 30470574 from the Natural Science Foundation of China and Grant 7052035 from the Natural Science Foundation of Beijing to H.S., as well as Grant BCS-0131829 from the NSF to P.L. Correspondence concerning this article should be addressed to Y. Liu, State Key Laboratory for Cognitive Neuroscience and Learning, Beijing Normal University, Beijing, China (e-mail: psykylin@gmail .com). 


\section{REFERENCES}

AIKEN, L. S., \& WeST, S. G. (1991). Multiple regression: Testing and interpreting interactions. Thousand Oaks, CA: Sage.

Balota, D. A., Cortese, M. J., Sergent-Marshall, S. D., Spieler, D. H., \& YAP, M. J. (2004). Visual word recognition of single-syllable words. Journal of Experimental Psychology: General, 133, 283-316.

Barbarotto, R., Laiacona, M., \& Capitani, E. (2005). Objective versus estimated age of word acquisition: A study of 202 Italian children. Behavior Research Methods, 37, 644-650.

Barca, L., Burani, C., \& Arduino, L. S. (2002). Word naming times and psycholinguistic norms for Italian nouns. Behavior Research Methods, Instruments, \& Computers, 34, 424-434.

Bates, E., Burani, C., D’ Amico, S., \& Barca, L. (2001). Word reading and picture naming in Italian. Memory \& Cognition, 29, 986-999.

Chalard, M., Bonin, P., Méot, A., Boyer, B., \& Fayol, M. (2003). Objective age-of-acquisition (AoA) norms for a set of 230 object names in French: Relationships with psycholinguistic variables, the English data from Morrison et al. (1997), and naming latencies. European Journal of Cognitive Psychology, 15, 209-245.

Chen, B. G., \& Peng, D. L. (1998). The influence of concreteness on word recognition [in Chinese]. Acta Psychologica Sinica, 30, 387-393.

Chen, B. G., Wang, L. X., Wang, L. L., \& Peng, D. L. (2004). The influence of age of acquisition and word frequency on word recognition [in Chinese]. Psychological Science, 27, 1060-1064.

COHEN, J., \& CoHEN, P. (1983). Applied multiple regression/correlation analyses for the behavioral sciences (2nd ed.). Hillsdale, NJ: Erlbaum.

Ellis, A. W., \& Lambon RalPh, M. A. (2000). Age of acquisition effects in adult lexical processing reflect loss of plasticity in maturing system: Insights from connectionist network. Journal of Experimental Psychology: Learning, Memory, \& Cognition, 26, 1103-1123.

Forster, K. I., \& Forster, J. C. (2003). DMDX: A Windows display program with millisecond accuracy. Behavior Research Methods, Instruments, \& Computers, 35, 116-124.

Frost, R. (1998). Toward a strong phonological theory of visual word recognition: True issues and false trails. Psychological Bulletin, 123, 71-99.

Hair, J., Black, W., Babin, B., Anderson, R., \& Tatham, R. (2006). Multivariate data analysis (6th ed.). Upper Saddle River, NJ: Pearson Prentice Hall.

Hernandez, A., \& LI, P. (2007). Age of acquisition: Its neural and computational mechanisms. Psychological Bulletin, 133, 1-13.

HoosaIn, R. (1992). Psychological reality of the word in Chinese. In H.-C. Chen \& O. J. L. Tzeng (Eds.), Language processing in Chinese (pp. 111-130). Amsterdam: North-Holland.

Lambon RalPh, M. A., \& Ehsan, S. (2006). Age of acquisition effects depend on the mapping between representations and the frequency of occurrence: Empirical and computational evidence. Visual Cognition, 13, 928-948

LeCK, K. J., WeEkES, B. S., \& CHEN, M. J. (1995). Visual and phonological pathways to the lexicon: Evidence from Chinese readers. Memory \& Cognition, 23, 468-476.

Li, P., Farkas, I., \& MacWhinney, B. (2004). Early lexical development in a self-organizing neural network. Neural Networks, $\mathbf{1 7}$ 1345-1362.

LI, P., JiN, Z., \& TAN, L. H. (2004). Neural representations of nouns and verbs in Chinese: An fMRI study. NeuroImage, 21, 1533-1541.

LI, P., \& YIP, M. C. (1998). Context effects and the processing of spoken homophones. Reading \& Writing, 10, 223-243.

LI, Y., \& KANG, J. S. (1993). Analysis of the phonetic parts of the ideophonetic characters in Modern Chinese. In Y. Chen (Ed.), Information analysis of the usage of characters in modern Chinese (pp. 84-98). Shanghai: Shanghai Education Publisher.

LiU, Y. Y., Zhang, L. J., \& SHU, H. (2006). The role of initial phoneme on naming latency [in Chinese]. Psychological Science, 29, 64-67.

LukAtela, G., \& TuRvey, M. T. (1994). Visual lexical access is initially phonological: 1. Evidence from associative priming by words, homophones, and pseudohomophones. Journal of Experimental Psychology: General, 123, 107-128.

LuO, C. P., \& WANG, J. (2002). Putong yuyinxue gangyao [General phonetics: A primer]. Beijing: Commercial Press.

Morrison, C. M., Chappell, T. D., \& Ellis, A. W. (1997). Age of ac- quisition norms for a large set of object names and their relation to adult estimates and other variables. Quarterly Journal of Experimental Psychology, 50A, 528-559.

PENG, D., \& JiANG, H. (2006). Naming Chinese phonograms: From cognitive science to cognitive neuroscience. In P. Li, L. Tan, E. Bates, \& O. J. L. Tzeng (Eds.), Handbook of East Asian psycholinguistics: Vol. 1. Chinese (pp. 346-357). Cambridge: Cambridge University Press.

People's Education Press (2006). Standard textbooks for nine-year elementary to high school education. Beijing: People's Education Press.

Pérez, M. A., \& Navalón, C. (2005). Objective AoA norms for 175 names in Spanish: Relationships with other psycholinguistic variables, estimated AoA, and data from other languages. European Journal of Cognitive Psychology, 17, 179-206.

SCIENCE Publishers (1988). Dictionary of Chinese character information. Beijing: Science Publishers.

Shibahara, N.,Zorzi, M.,Hill, M. P., Wydell, T., \&Butterworth, B. (2003). Semantic effects in word naming: Evidence from English and Japanese Kanji. Quarterly Journal of Experimental Psychology, 56A, 263-286.

Shu, H., Chen, X., Anderson, R. C., Wu, N. N., \& Xuan, Y. (2003). Properties of school Chinese: Implications for learning to read. Child Development, 74, 27-47.

SPieler, D. H., \& Balota, D. A. (2000). Factors influencing word naming in younger and older adults. Psychology \& Aging, 15, 225-231.

Strain, E., Patterson, K., \& Seidenberg, M. S. (1995). Semantic effects in single-word naming. Journal of Experimental Psychology: Learning, Memory, \& Cognition, 21, 1140-1154.

Strain, E., Patterson, K., \& Seidenberg, M. S. (2002). Theories of word naming interact with spelling-sound consistency. Journal of Experimental Psychology: Learning, Memory, \& Cognition, 28, 207-214.

Sun, H. L., Huang, J. P., Sun, D. J., Li, D. J., \& XING, H. B. (1997). Introduction to language corpus system of modern Chinese study. In M. Y. Hu (Ed.), Paper collection for the Fifth World Chinese Teaching Symposium. Beijing: Peking University Publisher.

Sun, M. (2006). Balanced corpus of modern Chinese. Tsinghua University AI and NLP Group (nlp.csai.tsinghua.edu.cn).

Van Orden, G. C., Pennington, B. F., \& Stone, G. O. (1990). Word identification in reading and the promise of subsymbolic psycholinguistics. Psychological Review, 97, 488-522.

WANG, H. (1986). Modern Chinese frequency dictionary. Beijing: Beijing Language Institute Press.

XING, H., SHU, H., \& LI, P. (2004). The acquisition of Chinese characters: Corpus analyses and connectionist simulations. Journal of Cognitive Science, 5, 1-49.

Young, G., \& Perkins, W. B. (2005). Presidential rhetoric, the public agenda, and the end of presidential television's "Golden Age." Journal of Politics, 67, 1190-1205.

Zhang, Q., \& Zhang, B. Y. (1997). Concreteness effect in Chinese double-character processing [in Chinese]. Psychological Science, 29, 216-224.

Zhang, Y., Wu, N., \& YIP, M. (2006). Lexical ambiguity resolution in Chinese sentence processing. In P. Li, L. H. Tan, E. Bates, \& O. J. L. Tzeng (Eds.), The handbook of East Asian psycholinguistics: Vol. 1. Chinese (pp. 268-280) Cambridge: Cambridge University Press.

Zноu, X., SHU, H., BI, Y. C., \& SHI, D. F. (1999). Is there phonological mediated access to lexical semantics in reading Chinese? In J. Wang, A. W. Inhoff, \& H. C. Chen (Eds.), Reading Chinese script (pp. 135172). Mahwah, NJ: Erlbaum.

Ziegler, J. C., Tan, L. H., Perry, C., \& Montant, M. (2000). Phonology matters: The phonological frequency effect in written Chinese. Psychological Science, 11, 234-238.

ZIPF, G. (1932). Selective studies and the principle of relative frequency in language. Cambridge, MA: Harvard University Press.

\section{NOTES}

1. The notion of "word" in Chinese is somewhat fuzzy in comparison with the idea in English (see Hoosain, 1992). Instead, a character is the most basic orthographic unit, which corresponds to a morpheme and often a monosyllabic word in the spoken language (what we call a "single-character word" here). Words can also consist of two characters 
(disyllabic), three characters (trisyllabic), and so on. The variable "number of word formations" (NWF) refers to the number of multisyllabic words that the same character can form.

2. Our age of acquisition (AoA) scores are based on participants' ratings of the age at which characters are acquired, a method that is typically used in AoA research. There is some debate about whether subjective ratings or objective AoAs (as derived from child language corpora) can better predict word naming and picture naming (see Barbarotto, Laiacona, \& Capitani, 2005; Chalard, Bonin, Méot, Boyer, \& Fayol, 2003; Morrison, Chappell, \& Ellis, 1997; Pérez \& Navalón, 2005). No large-scale objective AoAs exist yet for Chinese characters or words. It should also be noted that our participants ranged in age from 18 to 23 years (college students), which could potentially limit the generalizability of AoA effects on word naming (see Spieler \& Balota, 2000, about factors that might influence word naming in younger and older adults).

3. "Centering" here means the subtraction of each observation or measurement from the mean of a given variable, which allows the researcher to get deviation scores. Centering can reduce multicollinearity among predictor variables, especially when the interaction between two continuousvariable predictors is considered. See Aiken and West (1991) for details.

(Manuscript received December 8, 2006; accepted for publication January 23, 2007.) 